\title{
Report of a New Case of Interlocking Heads in a Breech-Vertex Twin Delivery: A Conversation with My Residents
}

\author{
Mamour Gueye*, Mouhamadou Wade, Aissatou Mbodji, Mame Diarra Ndiaye, \\ Ndiémé Mbaye, Mor Talla Ndiaye, Rahadat Ibrahim, Amadou Lamine Cisse, \\ Aliou Djiby Dia, Aliou Cisse, Moussa Diallo, Omar Gassama, Ousmane Thiam, \\ Magatte Mbaye
}

Philippe Senghor Health Center, Cheikh Anta Diop University, Dakar, Senegal

Email: ^mamourmb@yahoo.fr

How to cite this paper: Gueye, M., Wade, M., Mbodji, A., Ndiaye, M.D., Mbaye, N., Ndiaye, M.T., Ibrahim, R., Cisse, A.L., Dia, A.D., Cisse, A., Diallo, M., Gassama, O., Thiam, O. and Mbaye, M. (2021) Report of a New Case of Interlocking Heads in a Breech-Vertex Twin Delivery: A Conversation with My Residents. Open Journal of Obstetrics and Gynecology, 11, 40-47. https://doi.org/10.4236/ojog.2021.111005

Received: December 20, 2020

Accepted: January 19, 2021

Published: January 22, 2021

Copyright $\odot 2021$ by author(s) and Scientific Research Publishing Inc. This work is licensed under the Creative Commons Attribution International License (CC BY 4.0).

http://creativecommons.org/licenses/by/4.0/

\begin{abstract}
"Locked twins" is a rare event occurring in about 1 in every 1000 twin births. A 21-year-old primigravida with a 31-week twin pregnancy was admitted for delivery. The head of the first twin was locked to the chin of the second twin at the top of the symphysis pubis. Caesarean section was performed allowing the delivery of both dead twins. Twins gestations with first twin in the breech presentation raise index of suspicion of potential locked twin. However, management of such situation is controversial with most authors and colleges recommending caesarean section to avoid interlocking heads. We report another rare case of interlocking heads and bring up the topic about management of breech-first twin deliveries.
\end{abstract}

\section{Keywords}

Interlocking Heads, Breech Presentation Twins, Recommendations

\section{Introduction}

Multiple pregnancies have increased for the last three decades due to a growing use of assisted reproductive techniques and the rise in maternal age [1]. Twin gestations comprise approximately $1 \%$ of all pregnancies worldwide [2]. In around $20 \%$ of these pregnancies, the first twin is in breech presentation [3] whose delivery management is controversial.

There are an increasing number of studies exploring the mode of delivery in breech-first presenting twins with neonatal and maternal prognosis variously 
appreciated according to the mode of delivery. This is due to the fact that, currently, no consensus exists regarding the optimal mode of delivery for twin gestations with breech twin A. Historically, caesarean section was performed for the risk of interlocking twins during childbirth of breech-vertex twins. This complication is however rare, even exceptional. Less than 200 cases have been reported in the literature since 1958, i.e. a frequency of 1/1000 twin deliveries [4] [5].

We report a new case of interlocking twins managed by caesarean section. As an obstetrician and Public Health specialist, I report our case and set out in the rest of this paper some concepts of epidemiology and health policies following a conversation I had with my residents, specializing doctors.

\section{Case}

A Saturday morning, while in my office, I was called upon into the labor ward for a twin delivery in a 21-year-old unbooked patient with a 31-week twin pregnancy. On arrival, the cervix was fully dilated, the first twin in breech presentation was being expelled (Figure 1(a)). A deep vaginal examination makes it possible to perceive the head of the second twin in the pelvic cavity. The diagnosis of interlocking heads was thus established and a cesarean section was decided. Both fetuses were dead.

The hysterotomy exposed the bodies of both twins. We managed to extract the head of the second twin which was in the pelvic excavation and then extract it by cephalic enucleation. This was a fresh, female stillborn weighing $1275 \mathrm{~g}$. We then proceeded to the delivery of the first twin, a fresh stillborn male weighing $1980 \mathrm{~g}$. This was a dichorionic diamniotic twin pregnancy with the placenta being formed of two partially fused placentae.

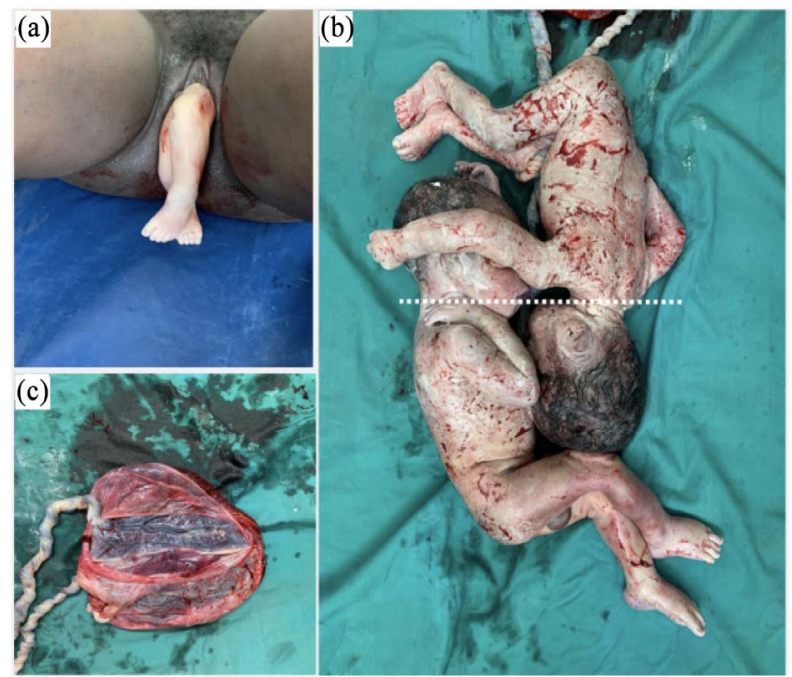

Figure 1. Locked twins and their fused placentae. (a): Legs of twin A partially delivered; (b): Locked twins-The head of twin A above the symphysis pubis is locked to the chin of twin B whose head is engaged and below the symphysis pubis, in the pelvic canal in the vagina; (c): Partially fused placentae. Dotted line: Represents the symphysis pubis with the head of Twin A above. 


\section{Comments}

Resident: This is the first time I come across this situation. How does it happen?

Me: To understand the mechanism of occurrence, I reconstruct the situation in Figure 1.

"Locked twins" is a condition occurring with breech/vertex twins, when the body of twin A delivers, but the chin "locks" behind the chin of twin B. There are two main types: breech/vertex and vertex/vertex. In the breech/vertex presentations, which are much more common, the first twin is in the breech position, presenting the feet first, and the second is in the vertex position [6]. In these cases, the chin of the first twin locks behind the chin of the second twin while it is in the uterus or in the birth canal, preventing vaginal birth [6]. In vertex/vertex presentations, where both twins are positioned for a head-first delivery, both heads lock at the edge of the pelvis, preventing either foetus from passing through the pelvic entrance during vaginal birth [7].

Factors contributing to interlocking twins include uterine hypertonicity, small foetal size, and reduced levels of amniotic fluid after rupture of membranes [6] [8] [9]. It is more likely to occur in women with a large pelvis, young primigravidae, and pregnancies with monoamniotic twins [6] [8] [9].

\section{Resident: How often does such an accident occur?}

Me: Interlocking heads is an are extremely rare situation, even exceptional and generally occurs in about 1 in every 1000 twin births. Less than 200 cases have been reported in the literature since 1958 [4] [5] [7].

\section{Resident: How interlocking twins are managed?}

Me: If locked twins are diagnosed early in labor, before either twin is born, both fetuses can be delivered by cesarean section. If a fetus has been partially born, attempts can be made to disimpact the twins manually, such as by the $\mathrm{Za}$ vanelli maneuver, in order to achieve an assisted delivery with suction cup or forceps [10]. If the diagnosis is not made until after the death of the first twin locked in the birth canal, or if the first twin is not expected to survive, the first twin may be beheaded and his head raised to allow safe delivery of the second twin [11].

At least one case has been reported where hexoprenaline has been used to relax uterine smooth muscle in order to temporarily inhibit labor and disrupt the head of the fetus [12]. Recently, having used Isoflurane, Rezaie-Keikhaie et al. managed to unlock locked twins with the second twin in good condition [13].

As locked twins are often diagnosed in the late stages of delivery, it is often too late to intervene to save the life of the first twin and therefore there is a high rate of stillbirth, estimated to be over 50\% [13].

Resident: Should not twin pregnancy with the first twin in breech presentation be an indication for caesarean section?

Me: You have raised an important question! One might wonder why argue? Should we not simply accept, like vaccinations or asepsis, this new progress in 
medicine which makes it possible to avoid neonatal asphyxia, fetal trauma and perineal tears, while ensuring families and caregivers an appointment for the birth. In addition, locked twins could be avoided by cesarean delivery in all cases in which the first twin is not in vertex [6]. The answer is that caesarean section is not the safest method of delivery, neither for the child nor for the mother, since maternal mortality is $1 \%$ to $3 \%$, a risk four to ten times that of vaginal delivery [14]. Data from countries like Finland, where the Caesarean section rate is particularly low, show low neonatal mortality. In the United States, the rate of caesarean sections is 4 times higher than in Ireland, but perinatal mortality is comparable in these two countries.

Given the risk of morbidity and mortality associated with caesarean sections, controlling the rate of caesarean section is a major concern in obstetrics. We must rely on evidence to decide.

Resident: Exactly, from how many cases of interlocking twins should we perform caesarean for all breech-first twin pregnancies?

Me: Making an informed medical choice requires weighing the potential benefits of treatment or medical intervention against the potential harm. But how do we know to what extent a patient is likely to benefit from treatment or medical intervention? To answer this question, statistical tools are available to us, including the number of subjects to be treated or Number Needed to Treat (NNT). The NNT tells us how many people we need to give a drug or other procedure for one person to receive a benefit (or to avoid a single unwanted outcome). To calculate the NNT, one must first know the absolute risk reduction. The absolute risk should be distinguished from the relative risk. If in a study, $1.7 \%$ of people taking or having benefited from treatment A experienced an adverse event $\mathrm{E}$, while $2.9 \%$ of the placebo group had one. The relative risk reduction, is the ratio of the two risks and is calculated by subtracting the rate of treatment A adverse events (1.9) from the rate in the placebo group (2.9) and dividing the difference (1.0) by the rate of the placebo group (2.9). This equates to $34 \%$. But the absolute risk reduction is calculated by simply subtracting the two risks, so $(2.9 \%-1.9 \%$ $=1.0 \%)$. In fact, treatment $\mathrm{A}$ reduced the risk of event $\mathrm{E}$ from $3 \%$ to about $2 \%$, and that $1 \%$ difference is the number that people are interested in. The NNT is simply the inverse of the absolute risk reduction; it can be calculated by taking 100 and dividing it by absolute risk reduction: 100/1 $=100$. This means that 99 people have to take the drug, pay for it, run the risk of side effects and have no chance of any benefit from it. Of course, no one knows who will get this 1 in 100 chance who will benefit from it.

Coming back to our case, it is a matter of calculating the number of caesarean sections needed with all the risks that the caesarean section entails to avoid a case of interlocking heads. From 2010 to date (September 2020), our department has registered 50,754 deliveries with 1457 twin pairs and 1 case of interlocking heads. The rarity of this situation could not be the basis of indication for caesarean section.

Me: To sum up: the use of evidence 
The management of breech-first twins is still controversial. In diamniotic twin pregnancies with the first twin in the breech presentation, many controversies still remain due to the debate about management of vaginal breech delivery and the theoretical risk of interlocking foetal heads. A number of retrospective studies have reported an increased perinatal risk from attempted vaginal deliveries, and the rate of scheduled caesarean deliveries with breech presentation increased steadily until 2000. "Term Breech Trial", the randomized trial by Hannah et al. [15] published in October 2000 in The Lancet came to reinforce, even confirm definitively for some, this hypothesis. A dramatic change in clinical practice ensued, which had increased the rate of caesarean section in breech presentations worldwide for singleton and twin pregnancies in which the first twin was in breech presentation [16]. Expertise in vaginal breech delivery has decreased and many obstetricians are now graduating with minimal or no experience in vaginal breech delivery [16].

On the other hand, several practitioners shared their results to contradict Hanna's study results. However, these studies have small sample sizes and their statistical analysis lacks power. In their meta-analysis of studies from 1980 to 2001, Hogle et al. [17] could only retain four studies out of 67. Two of these studies related to the first twin in the breech presentation [18] [19]. None were randomized, and all were retrospective cohort studies. These studies showed a significantly higher rate of scheduled caesareans in nulliparous women, parity being a factor significantly associated with the mode of delivery. In contrast, the low Apgar index scores at five minutes were significantly lower in the caesarean section group. The other outcomes (neonatal and perinatal mortality, morbidity) did not vary according to the mode of delivery. The authors concluded that it is advantageous to set up a planned caesarean section policy in first breech presenting twins, as in the general population (by extrapolating the results of the Hannah et al's study [15] to twinning). They also concluded that there was a risk of bias in their results due to the lack of randomization and the small sample sizes.

With the exception of the Term Breech Trial, no significant experimental studies on the safety of planned vaginal breech delivery has been yet performed. The most significant observational study (PREMODA) carried out prospective data collection on 8105 consecutive cases of women with a breech foetus who delivered in 174 centres in France and in Belgium over a one-year period [20]. The results of the PREMODA study showed no difference in perinatal mortality rates between planned vaginal breech delivery and planned caesarean section (0.8/1000 vs. $1.5 / 1000)$, or short-term neonatal morbidity (1.6\% vs. $1.45 \%)$.

In the study by Bourtembourg et al. [4], the authors observed no difference in neonatal outcomes in the caesarean section group compared to the vaginal delivery group. On the other hand, they noticed a significant difference in the mode of delivery as a depending on parity.

Sibony et al. [21] in 2005 studied the mode of delivery and neonatal morbidity of 614 twin pregnancies according to their presentation with a vaginal delivery 
rate of $82 \%$ ( $60 \%$ to $70 \%$ in most series). These authors do not consider that the first twin in breech presentation is an indication for a priori caesarean section, due to the extreme rarity of complications such as twin dystocia, and the lack of difference in obstetrical and neonatal prognosis observed in their series. They recommend the vaginal route when the first breech is breech after radiopelvimetry and the delivery is under the supervision of a skilled obstetrician.

Who should one follow? It is important to stress that these decisions are personal and that different people may make different decisions about treatment based on the same information.

Ideally, any medical intervention, whether diagnostic or therapeutic, should be justified by a set of randomized studies all of which have reached the same conclusion. It would happen in a perfect world. Also, we rarely have evidence of this level. And yet, in practice, whatever the corresponding levels of evidence, the practitioner must make diagnostic and therapeutic decisions in the face of a syndrome or a pathology.

\section{Conclusion}

Interlocking heads is an exceptional situation in Obstetrics, the management of which depends on the time of diagnosis. In preterm or monochoric twin pregnancies with the first twin in breech presentation, this situation should be a dread and increased clinical monitoring and ultrasound initiated if vaginal delivery is decided.

\section{Conflicts of Interest}

The authors have nothing to declare.

\section{References}

[1] Cruikshank, D.P. (2007) Intrapartum Management of Twin Gestations. Obstetrics \& Gynecology, 109, 1167-1176. https://doi.org/10.1097/01.AOG.0000260387.69720.5d

[2] Barret, J. and Bocking, A. (2000) The SOGC Consensus Statement: Management of Twin Pregnancies. Journal of Obstetrics and Gynaecology Canada, 22, 623. https://doi.org/10.1016/S0849-5831(16)30127-6

[3] Vadhera, R.B. and Locksmith, G.J. (2004) Breech Presentation, Malpresentation, and Multiple Gestation. In: Datta, S. and Hepner, D.L., Eds., Anesthetic and Obstetric Management of High-Risk Pregnancy, Springer, New York, 67-86.

[4] Bourtembourg, A., Ramanah, R., Jolly, M., Gannard-Pechin, E., Becher, P., Cossa, S., et al. (2012) [L'accouchement gemellaire en cas de premier jumeau en presentation podalique. Etude d'une serie continue de 137 cas]. Twin Delivery with the First Twin in Breech Position. A Study of 137 Continuous Cases. Journal de Gynécologie Obstétrique et Biologie de la Reproduction, 41, 174-181. https://doi.org/10.1016/j.jgyn.2011.10.005

[5] Pons, J.C. and Hoffmann, P. (2000) [La césarienne a-t-elle une indication en cas de grossesse gémellaire?]. Does Cesarean Section Have an Indication for Twin Pregnancies? Journal de Gynécologie Obstétrique et Biologie de la Reproduction, 29, 
40-50.

[6] Borah, T. and Das, A. (2012) Locked Twins: A Rarity. Annals of Medical and Health Science Research, 2, 204-205. https://doi.org/10.4103/2141-9248.105676

[7] Nissen, E.D. (1958) Twins: Collision, Impaction, Compaction, and Interlocking. Obstetrics \& Gynecology, 11, 514-526.

[8] El Deiry, S.K. (1960) Two Cases of Locked Twins. British Medical Journal, 1, 1174-1177. https://doi.org/10.1136/bmj.1.5180.1174

[9] Salmon, Y.M. (1968) Locked Twins-Report of 2 Cases. Singapore Medical Journal, 9, 89-91.

[10] Saad, F.A. and Sharara, H.A. (1997) Locked Twins: A Successful Outcome after Applying the Zavanelli Manoeuvre. Journal of Obstetrics and Gynaecology, 17, 366-367. https://doi.org/10.1080/01443619750112853

[11] Kock, J., van der Walt, C. and Jones, C.M. (2004) Maternal and Newborn Care: A Complete Guide for Midwives and Other Health Professionals. Juta Academic, Lansdowne.

[12] Sevitz, H. and Merrell, D.A. (1981) The Use of a Beta-Sympathomimetic Drug in Locked Twins. BJOG: An International Journal of Obstetrics \& Gynaecology, 88, 76-77. https://doi.org/10.1111/j.1471-0528.1981.tb00942.x

[13] Rezaie-Keikhaie, K. (2019) Successful Vaginal Delivery in Locked Twins: A Case Report. Iranian Journal of Nursing and Midwifery Research, 24, 156-157. https://doi.org/10.4103/ijnmr.IJNMR_44_18

[14] Deneux-Tharaux, C., Carmona, E., Bouvier-Colle, M.H. and Breart, G. (2006) Mortalité maternelle en France. BEH, 50, 392-402.

[15] Hannah, M.E., Hannah, W.J., Hewson, S.A., Hodnett, E.D., Saigal, S. and Willan, A.R. (2000) Planned Caesarean Section versus Planned Vaginal Birth for Breech Presentation at Term: A Randomised Multicentre Trial. The Lancet, 356, 1375-1383. https://doi.org/10.1016/S0140-6736(00)02840-3

[16] Kotaska, A. and Menticoglou, S. (2019) No. 384-Management of Breech Presentation at Term. Journal of Obstetrics and Gynaecology Canada, 41, 1193-1205. https://doi.org/10.1016/j.jogc.2018.12.018

[17] Hogle, K.L., Hutton, E.K., McBrien, K.A., Barrett, J.F. and Hannah, M.E. (2003) Cesarean Delivery for Twins: A Systematic Review and Meta-Analysis. American Journal of Obstetrics \& Gynecology, 188, 220-227.

https://doi.org/10.1067/mob.2003.64

[18] Blickstein, I., Goldman, R.D. and Kupferminc, M. (2000) Delivery of Breech First Twins: A Multicenter Retrospective Study. Obstetrics \& Gynecology, 95, 37-42. https://doi.org/10.1097/00006250-200001000-00008

[19] Grisaru, D., Fuchs, S., Kupferminc, M.J., Har-Toov, J., Niv, J. and Lessing, J.B. (2000) Outcome of 306 Twin Deliveries According to First Twin Presentation and Method of Delivery. American Journal of Perinatology, 17, 303-307. https://doi.org/10.1055/s-2000-13443

[20] Goffinet, F., Carayol, M., Foidart, J.-M., Alexander, S., Uzan, S., Subtil, D., et al. (2006) Is Planned Vaginal Delivery for Breech Presentation at Term Still an Option? Results of an Observational Prospective Survey in France and Belgium. American Journal of Obstetrics and Gynecology, 194, 1002-1011.

https://doi.org/10.1016/j.ajog.2005.10.817

[21] Sibony, O., Touitou, S., Luton, D., Oury, J.F. and Blot, P. (2006) Modes of Delivery 
of First and Second Twins as a Function of Their Presentation. Study of 614 Consecutive Patients from 1992 to 2000. European Journal of Obstetrics \& Gynecology and Reproductive Biology, 126, 180-185.

https://doi.org/10.1016/j.ejogrb.2005.08.013 